\title{
Assessment of Cardiac and Renal Functions in Wistar Albino Rats Administered Carmoisine and Tartrazine
}

\author{
Olu Israel Oyewole*, Johnson Olaleye Oladele \\ Department of Biochemistry, Faculty of Basic and Applied Sciences, Osun State University, Osogbo, Nigeria
}

Email address:

ioluoye@yahoo.com (O. I. Oyewole)

${ }^{*}$ Corresponding author

\section{To cite this article:}

Olu Israel Oyewole, Johnson Olaleye Oladele. Assessment of Cardiac and Renal Functions in Wistar Albino Rats Administered Carmoisine and Tartrazine. Advances in Biochemistry. Vol. 4, No. 3, 2016, pp. 21-25. doi: 10.11648/j.ab.20160403.11

Received: April 5, 2016; Accepted: April 14, 2016; Published: April 28, 2016

\begin{abstract}
Carmoisine and tartrazine are azo dyes widely used as food colourants. This study examine the effects of oral administration of carmoisine and tartrazine on some biochemical parameters in the heart and kidney of albino rats. Twenty four (24) female albino rats (average weight 140g) were sorted into four groups. Group A received water and served as the control, Group B-250mg $/ \mathrm{kg}$ bw carmoisine, Group C- $250 \mathrm{mg} / \mathrm{kg}$ bw tartrazine, Group D-co-administered $250 \mathrm{mg} / \mathrm{kg}$ bw each of carmoisine and tartrazine. The food dyes were administered daily for a period of 21 days. Results obtained showed a significant increase $(\mathrm{p}<0.05)$ in the levels of urea, creatinine and electrolytes $\left(\mathrm{Na}^{+}, \mathrm{K}^{+}\right.$and $\left.\mathrm{CO}_{3}{ }^{2-}\right)$ in the serum of rats administered the food dyes compared to control. The colourants also caused significant alterations $(p<0.05)$ in the levels of enzymes (creatine kinase, lactate dehydrogenase, aspartate aminotransferase and alkaline phosphatase) in the serum and heart homogenate of the experimental rats. Histological examination of the renal and cardiac tissues correlate with the biochemical results indicating marked distortions in the kidney and heart of rats administered carmoisine and tartrazine. These results suggest that carmoisine and tartrazine have the tendency of inducing nephrotoxicity and cardiac dysfunction in rats.
\end{abstract}

Keywords: Carmoisine, Tartrazine, Nephrotoxicity, Heart, Histology

\section{Introduction}

Food additives are chemicals added to foods with the aim of improving and enhancing their flavour, taste, colour, texture and for preservation [1]. They afford consumers the convenience and enjoyment of a wide variety of appetizing, nutritious, fresh, and palatable foods [2]. Additives are present in little quantities in foods but have great impact as many of them contain toxic components which when consumed repeatedly may result in alteration of normal cellular functions and induction of pathophysiological conditions such as cancer, atherosclerosis, diabetes etc. [3]. Many currently approved food dyes have been banned in some countries due to their adverse effects on laboratory animals and human [4-5].

Tartrazine

(Trisodium

1-(4-sulfonatophenyl)-4-(4-sulfonatophenylazo)-5-pyrazolone3 -carboxylate) is a synthetic yellow azo dye used primarily as a food colourant. Sensitivity symptoms has been reported to appear after 6 to 14 hours ingestion or cutaneous exposure to a substance containing tartrazine. Most allergic and intolerance reactions caused by tartrazine are similar to the ones caused by other azo dyes, in particular among asthmatics and aspirin intolerance individual. It was reported that children previously identified as hyperactive may exhibit increase in irritability, restlessness and sleep disturbance after exposure to tartrazine. Furthermore, mixture of tartrazine, ponceau, sunset yellow, carmoisine and sodium benzoate may cause hyperactivity in children [6].

Carmoisine also known as Azurubine (4-Hydroxy-3-(4-sulpho-1-naphthalenyl)azo)

-1-naphthalenesulphonic acid disodium) is a synthetic azo dye most widely used in heat-treated foods, condiments, candy, baked food products, ice cream and mouthwash. Carmoisine causes allergic or intolerance reactions particularly in individuals with aspirin intolerance. Other reactions may include rash similar to nettle rash and skin swelling [7]. Azo dyes have been reported to be carcinogenic and linked to bladder cancer [8]. This present study is designed to investigate 
the toxicity profile of single co-exposure of carmoisine and tartrazine in the kidney and heart of female albino rats.

\section{Materials and Methods}

\subsection{Reagents/Chemicals}

Carmoisine and tartrazine used in the experiment are products of Healthy Food Brands Ltd. England. Creatine kinase (CK), lactate dehydrogenase (LDH), aspartate aminotransferase (AST), alkaline phosphatase (ALP), urea and creatinine kits are products of Randox Chemical Limited, England. All other chemicals are of analytical grade.

\subsection{Experimental Design and Animal Grouping}

Twenty Four (24) female wistar albino rats (average weight $140 \mathrm{~g}$ ) were used for this experiment. They were obtained from the Department of Physiology, University of Ibadan, Nigeria and housed in the Central Animal House, Osun State University, Osogbo Nigeria. The rats were kept in ventilated cage at optimum temperature, $12 \mathrm{hrs}$ light/dark cycle and fed with commercial grower smash and water ad libitum. The experiment was carried out in accordance with current rules and guidelines established for care of laboratory animals. The rats were acclimatized for 2 weeks before administration commenced.

The animals were sorted into four (4) different groups containing six (6) rats each. Group A received water and serves as the control. Group B received $250 \mathrm{mg} / \mathrm{kg}$ bw carmoisine, Group C received $250 \mathrm{mg} / \mathrm{kg}$ bw tartrazine while group D were co-administered $250 \mathrm{mg} / \mathrm{kg}$ bw each of carmoisine and tartrazine. Administration of the food dyes lasted 21 days and was done using the oral gavage method.

\subsection{Animal Sacrifice and Collection of Blood}

The rats were sacrificed after $24 \mathrm{hrs}$ of last dose treatment under the influence of chloroform anesthesia. Blood were collected by cutting the jugular vein into plain bottles, allowed to clot and centrifuged at $4000 \mathrm{rpm}$ for $30 \mathrm{mins}$ to obtain the serum. The serum obtained was stored in a refrigerator at $-4^{\circ} \mathrm{C}$ until it was used for biochemical analysis.

\subsection{Preparation of Tissue Homogenate}

The heart and kidneys were immediately removed, rinsed with $\mathrm{KCl}$ and weighed. The heart were then homogenized in four volumes of the homogenizing buffer $(0.1 \mathrm{M}$ Tris- $\mathrm{KCl}$, $\mathrm{pH}$ 7.4) using a Teflon homogenizer. The resulting homogenate was centrifuged at $12,500 \mathrm{~g}$ for 15 minutes in a cold centrifuge $\left(4^{\circ} \mathrm{C}\right)$ to obtain the post mitochondrial fraction. The supernatant was collected and used for biochemical analyses.

\subsection{Histological Examination}

The kidney and heart were immediately fixed in $10 \%$ formalin and embedded in paraffin wax. Fine sections (7-9 $\mathrm{mm}$ thickness) of the kidney and heart were then dewaxed in xylene, hydrated in decreasing percentage of alcohol and stained with hematoxylin and eosin. The stained sections were observed under a Leitz microscope and their photomicrograph taken at X 400 with a Canon (Meville, NY) Power Shot G2 Digital Camera.

\subsection{Estimation of Biochemical Parameters}

Marker enzymes and metabolites were measured in the serum and heart homogenate of rats as appropriate using Randox diagnostic kits based on the principles earlier described: ALP [9], AST [10], CK [11], LDH [12], Urea [13] and Creatinine [14]. Serum sodium and potassium ions were measured by flame photometry while serum bicarbonate ion concentrations was determined by back titration as described by Tietz et al. [15].

\subsection{Statistical Analysis}

The results were analyzed using a statistical software package SPSS Version 12. Data were expressed as mean \pm standard error of the mean (mean \pm SEM). Student's t-test was employed for comparison between two sets of data. $\mathrm{P}<0.05$ was considered statistically significant.

\section{Results}

Table 1 show the mean organ weight index (X 100) of rats administered carmoisine and tartrazine. The kidney and heart weight of rats who received the dye combination were significantly increased compared with the control while there were no significant change in the liver and heart of rats who received single dye compared with the control. Serum concentrations of renal function indices in the rats is shown in Table 2. The results indicate that exposure of rats to carmoisine and tartrazine either singly or combined caused a significant $(\mathrm{p}<0.05)$ increase in the concentrations of urea, creatinine and electrolytes $\left(\mathrm{Na}^{+}, \mathrm{K}^{+}\right.$and $\left.\mathrm{HCO}_{3}{ }^{-}\right)$in the serum of the rats compared to the control. Table 3 show the serum concentrations of some cardiac function marker enzymes in the experimental rats. There was significant increase in the activities of the enzymes in the serum of rats administered the dyes compared with the control.

The activities of some cardiac function marker enzymes in the heart homogenate of experimental rats is shown in Table 4. The results indicate a significant $(\mathrm{p}<0.05)$ decrease in the activities of enzymes in the heart of rats who received the dyes compared to the control.

Table 1. Mean organ weight index (X 100) of rats administered carmoisine and tartrazine.

\begin{tabular}{lllll}
\hline Tissue & Control & Carmoisine & Tartrazine & Carmoisine + Tartrazine \\
\hline Kidney & $1.38 \pm 0.12$ & $1.41 \pm 0.20$ & $1.40 \pm 0.19$ & $1.88 \pm 0.27^{*}$ \\
Heart & $0.41 \pm 0.07$ & $0.44 \pm 0.06$ & $0.42 \pm 0.07$ & $0.88 \pm 0.10^{*}$ \\
\hline
\end{tabular}

Values are mean \pm SEM of six determinations. *Significantly different from the control at $\mathrm{p}<0.05$. 
Table 2. Serum concentrations of renal function indices in rats administered carmoisine and tartrazine.

\begin{tabular}{llllll}
\hline Experimental Groups & Urea $(\mathbf{m m o l} / \mathbf{L})$ & Creatinine $(\mathbf{m m o l} / \mathbf{L})$ & $\mathbf{~ N a}^{+}(\mathbf{m m o l} / \mathbf{L})$ & $\mathbf{K}^{+}(\mathbf{m m o l} / \mathbf{L})$ & $\mathbf{H C O}_{3}{ }^{-}(\mathbf{m m o l} / \mathbf{L})$ \\
\hline Control & $2.95 \pm 0.23$ & $51.00 \pm 2.43$ & $141.45 \pm 7.49$ & $37.64 \pm 2.73$ & $16.60 \pm 1.12$ \\
Carmoisine & $5.00 \pm 0.94^{*}$ & $67.75 \pm 3.90^{*}$ & $165.03 \pm 8.26^{*}$ & $45.32 \pm 3.12^{*}$ & $21.60 \pm 2.36^{*}$ \\
Tartrazine & $5.10 \pm 0.45^{*}$ & $64.30 \pm 4.02^{*}$ & $169.93 \pm 8.95^{*}$ & $44.73 \pm 3.47^{*}$ & $23.73 \pm 2.22^{*}$ \\
Carmoisine + Tartrazine & $5.53 \pm 0.66^{*}$ & $70.50 \pm 3.50^{*}$ & $173.66 \pm 9.72^{*}$ & $48.33 \pm 3.27^{*}$ & $27.06 \pm 2.89^{*}$ \\
\hline
\end{tabular}

Values are mean $\pm \mathrm{SEM}$ of six determinations. *Significantly different from the control at $\mathrm{p}<0.05$.

Table 3. Effect of carmoisine and tartrazine on some cardiac function marker enzymes in the serum of albino rats.

\begin{tabular}{lllll}
\hline Experimental Groups & ALP $(\mathbf{I U} / \mathbf{L})$ & AST $($ IU/L) & CK (IU/L) & LDH (IU/L) \\
\hline Control & $71.45 \pm 4.83$ & $91.76 \pm 4.12$ & $52.45 \pm 4.44$ & $146.42 \pm 9.66$ \\
Carmoisine & $84.51 \pm 4.66^{*}$ & $112.42 \pm 6.23^{*}$ & $67.23 \pm 5.95^{*}$ & $167.75 \pm 10.52^{*}$ \\
Tartrazine & $83.24 \pm 5.82^{*}$ & $109.64 \pm 6.80^{*}$ & $70.80 \pm 6.22^{*}$ & $164.28 \pm 10.76^{*}$ \\
Carmoisine + Tartrazine & $90.35 \pm 5.55^{*}$ & $116.56 \pm 8.12^{*}$ & $74.63 \pm 6.45^{*}$ & $170.55 \pm 11.63^{*}$ \\
\hline
\end{tabular}

Values are mean \pm SEM of six determinations. *Significantly different from the control at $\mathrm{p}<0.05$.

Table 4. Effect of carmoisine and tartrazine on some cardiac function marker enzymes in the heart homogenate of albino rats.

\begin{tabular}{lllll}
\hline Experimental Groups & ALP (IU/mg protein) & AST (IU/mg protein) & CK (IU/mg protein) & LDH (IU/mg protein) \\
\hline Control & $142.55 \pm 6.76$ & $956.81 \pm 14.52$ & $4.54 \pm 0.64$ & $86.56 \pm 5.43$ \\
Carmoisine & $122.46 \pm 8.33^{*}$ & $728.36 \pm 10.83^{*}$ & $3.65 \pm 0.34^{*}$ & $65.57 \pm 4.55^{*}$ \\
Tartrazine & $120.37 \pm 7.46^{*}$ & $733.54 \pm 11.68^{*}$ & $3.53 \pm 0.45^{*}$ & $64.34 \pm 3.98^{*}$ \\
Carmoisine + Tartrazine & $116.42 \pm 5.45^{*}$ & $722.30 \pm 09.23^{*}$ & $3.295 \pm 0.46^{*}$ & $62.91 \pm 4.04^{*}$ \\
\hline
\end{tabular}

Values are mean \pm SEM of six determinations. * Significantly different from the control at $\mathrm{p}<0.05$.
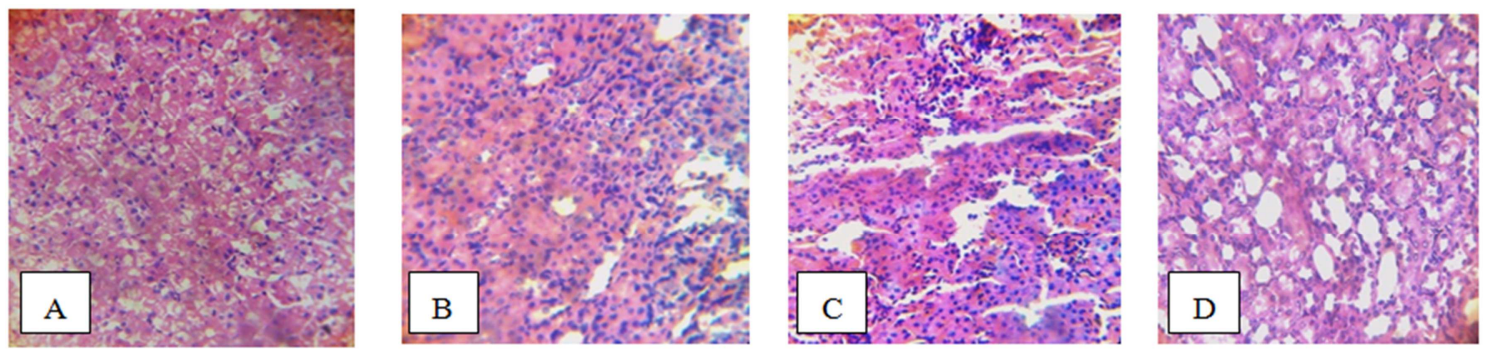

Figure 1. Photomicrographs of longitudinal section of the kidney of rats exposed to carmoisine and tartrazine (Haematoxylin and Eosin stain X 400).

A. Control rats (with no dye administered) showing normal architectural structure of the glomerular tubules with no visible lesion.

B. Rats administered $250 \mathrm{mg} / \mathrm{kg}$ bw carmoisine showing mild tubular necrosis and renal cortical congestion.

C. Rats administered $250 \mathrm{mg} / \mathrm{kg}$ bw tartrazine showing mild tubular necrosis and renal cortical congestion.

D. Rats co-administered $250 \mathrm{mg} / \mathrm{kg}$ bw each of carmoisine and tartrazine showing acute tubular necrosis and vascular congested kidney cells. The tubules around the glomeruli appear degenerated.
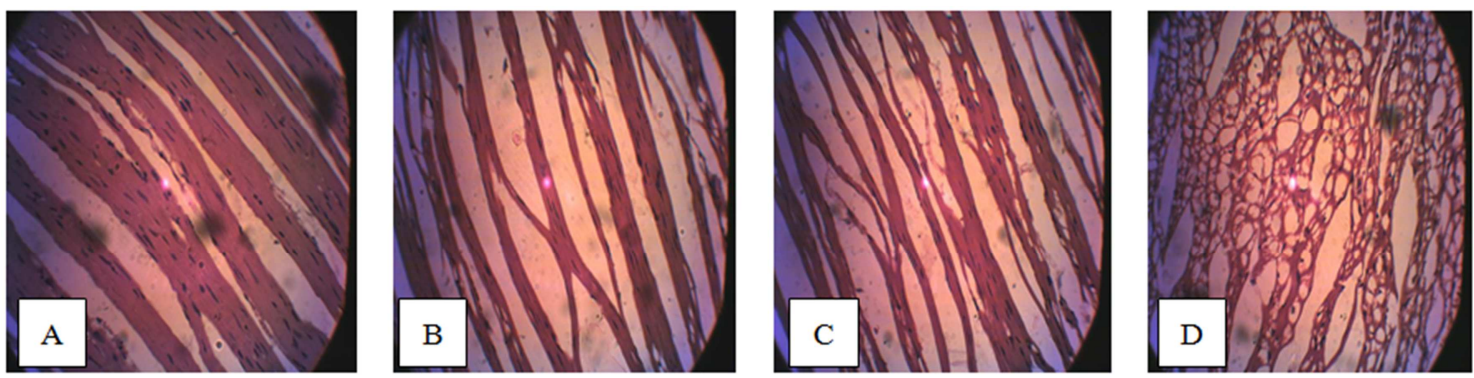

Figure 2. Photomicrographs of longitudinal section of cardiac tissues of rats exposed to carmoisine and tartrazine (Haematoxylin and Eosin stain X400).

A. Control rats (with no dye administered) showing normal architectural structure of the cardiac tissues with centrally located nuclei of cardiomyocytes and regularly arranged cardiac myofibres

B. Rats administered $250 \mathrm{mg} / \mathrm{kg}$ bw carmoisine showing deformation in sizes and shapes in the nuclei of the cardiomyocytes. Cardiac myofibres seen in disarrayed pattern

C. Rats administered $250 \mathrm{mg} / \mathrm{kg}$ bw tartrazine showing deformation in sizes and shapes in the nuclei of the cardiomyocytes. Cardiac myofibres seen in disarrayed pattern

D. Rats co-administered $250 \mathrm{mg} / \mathrm{kg}$ bw each of carmoisine and tartrazine deformation in sizes and shapes in the nuclei of the cardiomyocytes. Cardiac myofibres seen in disarrayed patter. Interstitial fibrosis was also observed as connective tissue deposits (blue stain). 


\section{Discussion}

Combined administration of carmoisine and tartrazine to rats (Group 4) caused significant increase in size of the kidney and heart above the normal (Table 1) which could be as a result of inflammation caused by accumulation of fat or protein within the tissues [16].

The observed elevation in the concentrations of urea, creatinine and electrolytes in the serum of rats treated with the dyes as compared to control is an indication of renal function impairment [17]. Urea and creatinine are important markers of the filtration function of the kidneys. They are excreted from the blood by the kidneys via glomerular filtration and their blood concentration correlates with the rate of glomerular filtration [18].

Serum urea has been reported to increase in acute and chronic intrinsic renal disease [19] and also when there is decreased effective circulating blood volume with decreased renal perfusion [20]. Increase in serum creatinine has also been reported to arise from intrinsic renal lesions, decreased perfusion of the kidney or obstruction of lower urinary tract [21]. Level of electrolytes in the serum is also useful in assessment of renal function. Elevated serum sodium levels have been attributed to intravascular haemolysis which is associated with renal failure [22].

The observed significant increase in the activities of enzymes (ALP, AST, CK and LDH) in the serum with their concomitant reduction in the heart of rats administered carmoisine and tartrazine is suggestive of cardiac tissues damage. Enzyme activities in tissues are often used as marker to ascertain early toxic effects of administered foreign compounds to experimental animals [23]. Elevation of these enzymes in the serum might be due to possible membrane damage or due to stress condition resulting into leakage of the enzymes from the heart into the serum. ALP is a membrane bound enzyme present in most tissues particularly those involved in active transport mechanisms. Elevated activity of serum ALP has been most consistently found in congestive heart failure in which ALP from cardiac cells is released into the bloodstream [24].

AST is widely distributed in animal tissues, being more concentrated in the liver, heart and skeletal muscle. As the concentration of AST is very high in the heart, large amount of the enzyme is released into the circulation in myocardial infarction [25]. Creatine kinase is a relatively muscle-specific cellular enzyme introduced into clinical use in 1959. The use of creatine kinase in the routine diagnosis of myocardial infarction was introduced by Sorensen [26] who found a distinct increase in this enzyme in the serum of patients with recent myocardial infarction which was confirmed by a number of other scientists [27].

LDH is an intracellular enzyme present in nearly all metabolizing cells with highest concentration in the heart, skeletal muscle and erythrocytes. The enzyme catalyzes the reversible conversion of muscle lactic acid into pyruvic acid, an essential step in the metabolic process that ultimately produces cellular energy. Cellular damage to the heart increases serum LDH although this increase may be influenced by other body tissues other than the heart. Therefore, LDH1 isoenzymes is normally used in assessing cardiac damage. If LDH1 isoenzyme is elevated in the serum, it is strongly indicative of myocardial infarction [28]. Serum level of LDH1 isoenzyme is elevated within 24-48 hours and reaches a peak in 48-72 hours after episode of myocardial infarction [29].

Histomicrograph of the kidney and heart of rats administered the dyes show significant histological distortions in their normal appearance and architecture. The cardiac tissues were characterized by deformed nuclei, disarray of myofibres and connective tissue deposits which might probably be due to degeneration of the structural protein in mitochondria of the cytoplasm [30]. The kidney of treated rats also indicate acute tubular necrosis and vascular congested cells with degenerated tubules. Rats who received the dyes combination was found to possess severe histological changes in the renal and cardiac tissues compared to the control.

\section{Conclusion}

Results documented in the study revealed that exposure of rats to carmoisine and tartrazine at these concentrations caused impairment of cardiac and renal functions and may constitute a risk factor for renal and cardiac disorders. We recommend that the use of these food additives be done with caution and should be properly monitored by relevant regulatory agencies.

\section{References}

[1] A. Downham and P. Collins. Colouring our foods in the last and next millennium. International Journal of Food Science and Technology. 2000, 35: 5-22.

[2] R. L. Newsome. Food colours. Food technology. 1986, 40 (7): 49-56.

[3] S. A. Soltan and E. M. Manal. The Effects of Using Colour Foods of Children on Immunity Properties and Liver, Kidney on Rats". Food and Nutrition Sciences. 2012, 3 (7): 897-904.

[4] J. Cook. Colorants compliance. The World of Food Ingredients Arnhem. The Netherlands. CNS Media. 2013, 41-43.

[5] H. Meggos. Food colours: an international perspective. The Manufacturing Confectioner. 1995, pp. 59-65.

[6] M. Donna. Food additives and hyperactive behaviour in 3-year-old and 8/9-year-old children in the community: a randomised, double-blinded, placebo-controlled trial. The Lancet. 2007, 370: 1560-1567.

[7] G. P. Ford, B. I. Stevenson and J. G. Evans. Long-term toxicity study of carmoisine in rats using animals exposed in vitro. Food Chem. Toxicol. 1987, 25 (12): 19-25. 
[8] K. I. Golka, S. Kopps, H. M. Prager, S. V. Mende, R. Thiel, O. Jungmann, J. Zumbe, H. M. Bolt, M. Blaszkewicz, J. G. Hengstler and S. Selinski. Bladder cancer in crack testers applying azo dye-based sprays to metal bodies. J Toxicol and Environmental Health. 2012, 75 (8-10): 566-571.

[9] P. J. Wright, D. T. Plummer and P. T. Leathwood. Enzyme in rat urine. Alkaline phosphatase. Enzymologia. 1972, $42: 317-327$

[10] S. Reitman and S. Frankel. A colorimetric method for the determination of serum glutamic oxaloacetate aminotransferase. Am. J. Clin. Pathol. 1957, 28:56-63.

[11] B. P. Hughes. A method for the estimation of serum creatine kinase and its use in comparing creatine kinase and aldolase activity in normal and pathological sera. Clin. chim. Acta, 1962, 7: 597.

[12] R. E. Vanderlinde. Measurement of total lactate dehydrogenase activities. Annals of Clinical Lab. Sci. 1985, 15 (1):13-31.

[13] D. R. D. Wybenga, J. Glorgio and V. J. Pileggi. Determination of serum urea by diacetyl monoxime method. J. Clin. Chem. 1971, 17: 891-895.

[14] R. J. Henry. Determination of serum creatinine. In: Clinical Chemistry: Principle and Technics. 2nd Edn. Harper and Row. 1974, p 525.

[15] N. W. Tietz, E. L. Pruden and O. Siggaard-Andersen. In: Tietz textbook of Clinical Chemistry (Burtis CA, Ashwell ER eds.) W.B Saunders Company London. 1994, 1354-1374.

[16] P. B. C. Friedman. Effect of diseases on clinical laboratory test. Am. Soc. Clin. Chem. J. 1980, 5(2):122-125.

[17] A. J. Patil, V. R. Bhagwat, J. A. Patil, N. N. Dongre, J.G. Ambekar and K. K. Das. Occupational lead exposure in battery manufacturing workers, silver jewelry workers and spray painters in Western Maharashtra (India): effects on liver and kidney function. J. Basic Clin. Physiol. Pharmacol. 2007, 18: 87-100.

[18] H. M. Wadei, M. L. Mai, N. Ahsan and T. A. Gonwa. Hepatorenal syndrome: Pathophysiology and management. Clin. J. Am. Soc. Nephro. 2006, 1 (5):1066-1079.
[19] J. S. Cameron and R. Greger. Renal function and testing of function. In Davison A. M, Cameron J. S., Grunfeld J. P., Kerr D. N. S., Rits E., Winearl G. C. eds Oxford textbook of Clinical Nephrology. 1998, Pp 36-39.

[20] S. R. Orth and E. Ritz. The nephritic syndrome. New England Journal of Medicine 1998, 338: 1202-1211.

[21] J. S. Bard. The kidney: from normal development to congenital disease. Boston: Academic Press. 2003, Pp.154.

[22] M. L. Halpperin and K. S. Kamel. Electrolyte Quinter: Potassium. Lancet. 1998, 352:135-140.

[23] A. A. Adesokan and M. A. Akanji. Effect of administration of aqueous extract of Enantia chlorantha on the activities of some enzymes in the small intestine of rats. Nig. J. Biochem. Mol. Biol. 2004, 18: 103-105.

[24] W. L. Clapp. Renal Anatomy. In: Zhou X. J., Laszik Z., Nadasdy T., D'Agati V. D., Silva F.G. eds. Silva's Diagnostic Renal Pathology. New York: Cambridge University Press. 2009.

[25] D. W. Moss and S.B. Rosalki. Enzyme tests in diagnosis. Edward Arnold. London. 1996, Pp. 68-77.

[26] N. S. Sorensen. Creatine phosphokinase in the diagnosis of myocardial infarction. Acta Med. Scand, 1963, 174,725.

[27] T. Wallimann, M. Wyss, D. Brdiczka, K. Nicolay and H. M. Eppenberger. Intracellular compartmentation, structure and function of creatine kinase isoenzymes in tissues with high and fluctuating energy demands: the phosphocreatine circuit for cellular energy homeostasis. The Biochemical Journal. 1992, 281(1): 21-40.

[28] C. Perry, H. Peretz, O. Ben-Tal, and A. Eldor. Highly elevated lactate dehydrogenase level in a healthy individual a case of macro-LDH American. J. Hematol, 1997, 55: 39-40.

[29] S. Neubauer. The Failing Heart: An Engine Out of Fuel. New England Journal of Medicine 2007, 356 (11): 1140-1151.

[30] M. G. Aymen. Introduction to functional and clinical histology, text and atlas, Part I, 4th ed. Giza, Egypt. 2000, 193-196. 